\title{
CORRIGENDUM
}

\section{Sex differences in glutamate receptor gene expression in major depression and suicide}

AL Gray, TM Hyde, A Deep-Soboslay, JE Kleinman and MS Sodhi

Molecular Psychiatry (2015) 20, 1139; doi:10.1038/mp.2015.114; published online 28 July 2015

Correction to: Molecular Psychiatry advance online publication, 14 July 2015; doi:10.1038/mp.2015.91

Following publication of this paper, the authors noticed that the Acknowledgements section was omitted from their paper. The complete Acknowledgement section follows:
Funded by the American Foundation for Suicide Prevention and a Hans W. Vahlteich Scholar's Award to MSS. 